\title{
Design for Schools
}

\author{
Domenico Chizzoniti, Luca Monica, Tomaso Monestiroli, Raffaella Neri \\ and Laura Anna Pezzetti
}

\begin{abstract}
Some competition projects concerning the construction of new schools are collected in this article. These projects deal with different themes depending on the level of education: high schools and secondary schools are generally integrated with collective services open to the city etc.- - open to the city to seat new important urban centers. On the other way round, primary schools and kindergartens are generally more introverted buildings, to protect the safety of children, so as the organization of space is more linked to educational patterns. In all cases, the schools are buildings that include open spaces, courtyards or gardens, which relate to the features of the different sites.
\end{abstract}

Keywords New schools $\cdot$ Education $\cdot$ Urban role $\cdot$ Social role

\section{Introduction}

Schools are civil institutions and, as such, can become urban landmarks facilitating the construction of new public places. This role determines the order of problems facing the school project: first, it is necessary to clarify the relationship with the places where it is located and with the other elements of the city. Architecture must always be considered as a tool for building places, the features of which, in the case of schools, vary considerably depending on their rank, and therefore their possible opening up to the city.

In this sense, the typological question becomes decisive: the school is a building having common spaces and spaces reserved for smaller groups, with classes which we could say are more private, just like a home, a collective home. It is therefore essential to define the central place which identifies it, its common space, one which will most likely establish a privileged relationship with its external urban spaces; and then the relationship of the collective space with the classrooms, its internal organisation, which is to be considered in terms of the educational system.

D. Chizzoniti · L. Monica · T. Monestiroli $(\bowtie) \cdot$ R. Neri · L. A. Pezzetti

Architecture, Built Environment and Construction Engineering-ABC Department,

Politecnico di Milano, Milan, Italy

e-mail: tomaso.mnestiroli@polimi.it 
The last but crucial issue relates to the construction methods. These must make these relationships tangible, if one considers that the building is not only a technical element but also the means of expression of its architecture, through which to express the building's identity, the very idea of the school and the quality of the places that it defines.

\section{Primary School and Lower Secondary School in the Muncipality of Monreale (PA) 2016 $^{1}$}

\section{@ Scuole Innovative-National Competition, 1st Prize}

The area allocated to the new school district in Monreale is situated south of the historic centre. It is a rugged area fully overlooking the natural landscape of the Oreto River plain and the Gulf of Palermo. These features make the area an impressive place which can be further enhanced by the settlement of a public building whose value goes beyond its own use but benefits from the environmental quality of the place where it stands.

The specification in the competition notice regarding the need to open the school to the community was the starting point of the whole project for us.

The school building becomes one of the urban centres of reference for the citizens of Monreale: the auditorium, gymnasium, educational gardens, the Stoa, the library, theatre spaces, the square and the cloister are all places open to the city independently from the school's operation.

The school's new square overlooks the edge of the historic centre and the impressive monumental complex of the cathedral.

The typological choice underlying the project is the construction of a "Stoa" facing the landscape, which is the distribution axis of the internal school complex. The individual elements of the school are connected to the Stoa: to the north, in direct relation to the city and creating the new street facade is the Auditorium, the block of workshops open to the city, the entrance hall and the gymnasium; to the south, in correspondence with the entrance hall, lies the large teaching cloister around which the primary and secondary school classrooms and laboratories are organised.

The idea is to build the school as a communal place of integration between cultures and thus, in all respects, like a small town. A structure that is built starting from the relationship between public places and private places, streets and squares and covered spaces and open spaces, all in direct contact with nature and the landscape.

Thus, the Cloister, which all classrooms and laboratories overlook and is located at a lower level to the entrance, becomes the student's square, an Agora of culture where collective activities can be shared and fun and recreational activities held (Fig. 1).

\footnotetext{
${ }^{1}$ Team work: Tomaso Monestiroli, Luca Cardani, Riccardo Nana, Giovanni Uboldi.
} 


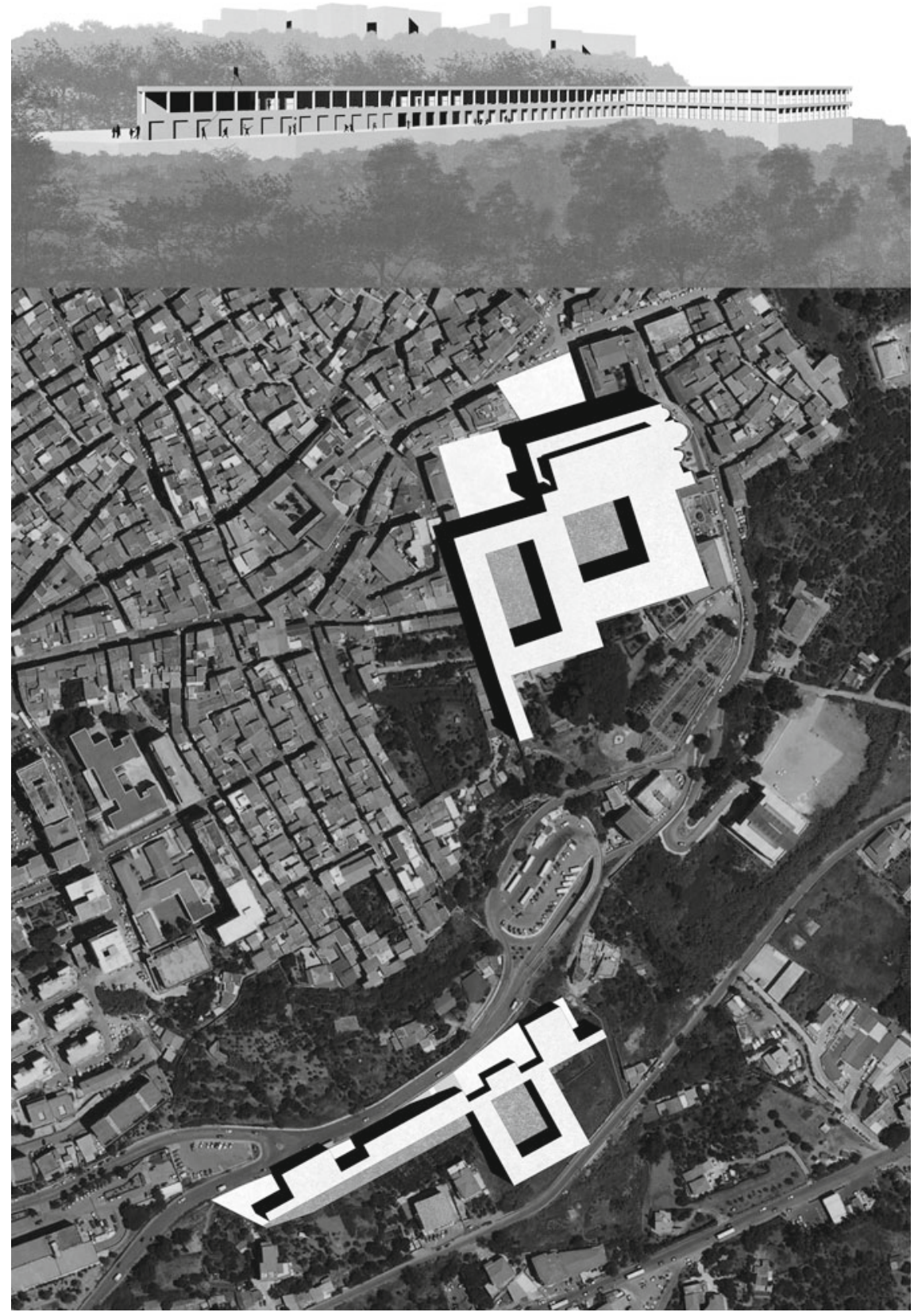

Fig. 1 General view and general plan 


\section{Innovative School Complex for Monreale, Palermo, 2016 ${ }^{2}$}

\section{@ Scuole Innovative-National Competition}

School Building represents a fundamental architectural resource to set up a place around which the civic dimension of the community can gather. An essential element for the design of Monreale's "Innovative School" (2017) is the introduction of public spaces (such as a forecourt and a accessible roof) as founding element of the layout in an area otherwise isolated by the main settlement. The design is also assumed as a component to turn the criticality of the steep slope into an opportunity to enhance the landscape character through the association of the section and spatial configuration to the diagram of activities, reconnecting also with the lower valley settlement. The innovative characters of the learning spaces are not limited to the introduction of spatial flexibility, 3.0 devices and furnishings, but integrate them in a holistic reflection on the capacity of the architectural space to be educator itself. Reacting to the concept of innovation as un unstructured learning environment, the design learned from the Monreale's Cathedral to define a clear prototype for the complex programme, centred on a nave and two circular "cloisters" and based on additional recognisable "space-places" and a plurality of "centres of attention". Those are attractors of multiple activities for informal socialisation and learning and are equipped with various types of patios. Sustainability and bioclimatic principles have generated a logical coherence of technical, constructive and material choices, offering an eco-efficient performance of the building in all phases of the Life Cycle: recyclable materials, integration of renewables ( $80 \%$ of energy needs for heating with photovoltaic), passive systems of natural ventilation and control of visual comfort, spatial flexibility and acoustic comfort. The reduced structural masse of the wooden structural system, the box-like structure and the shapes intrinsically provide the building with an effective anti-seismic behaviour (Figs. 2, 3-4, 5, 6).

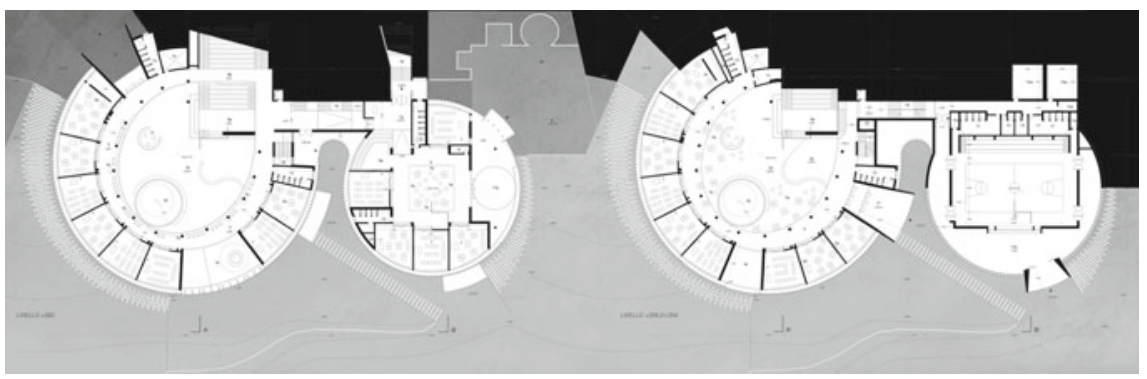

Fig. 2 Plans of the school complex (middle and primary school and gym) at levels +283 and + 259

\footnotetext{
${ }^{2}$ Team work: Laura Anna Pezzetti (architectural design); Carol Monticelli and Alessandra Zanelli (technology); Claudio Del Pero (energy); G. Piantato (structures).
} 

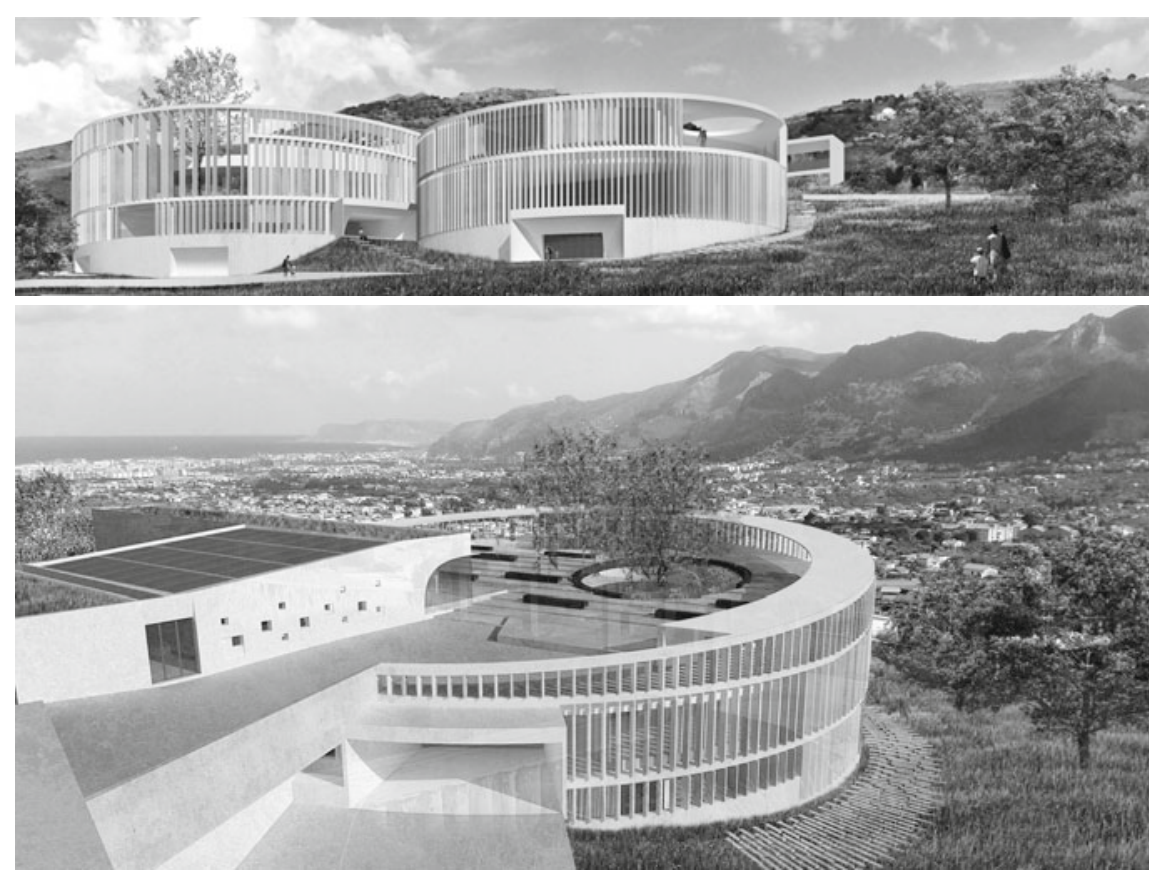

Figs. 3-4 View of the middle school's roof terrace looking towards Palermo and the sea

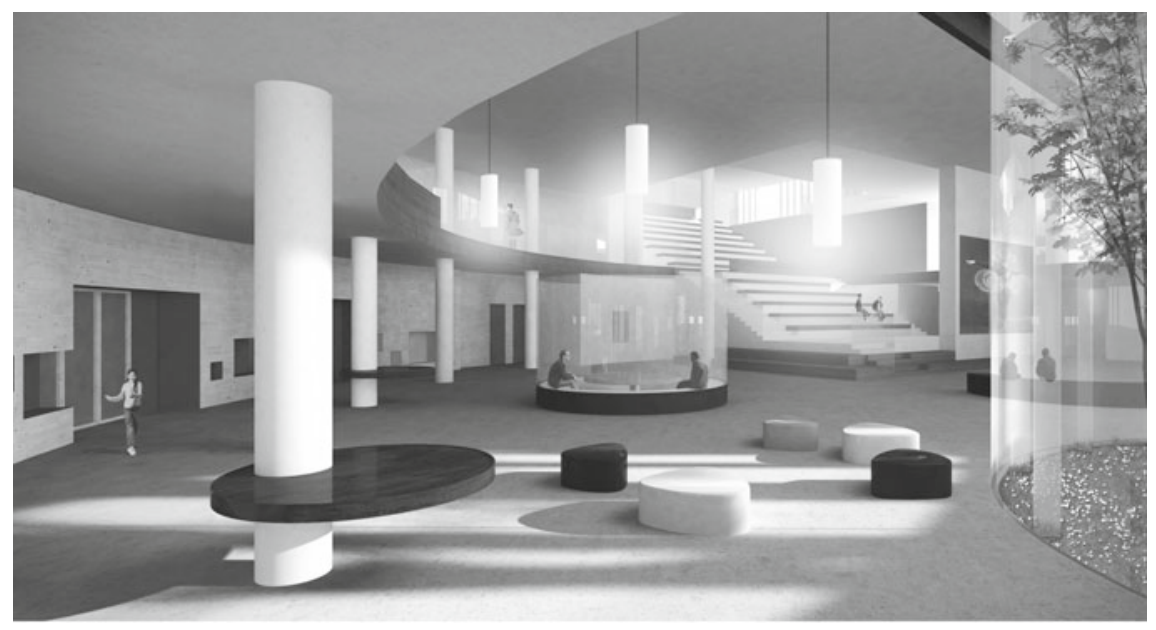

Fig. 5 View of the middle school's "core centre" with the equipped ring-shaped space and the stepped aisle of the auditorium 

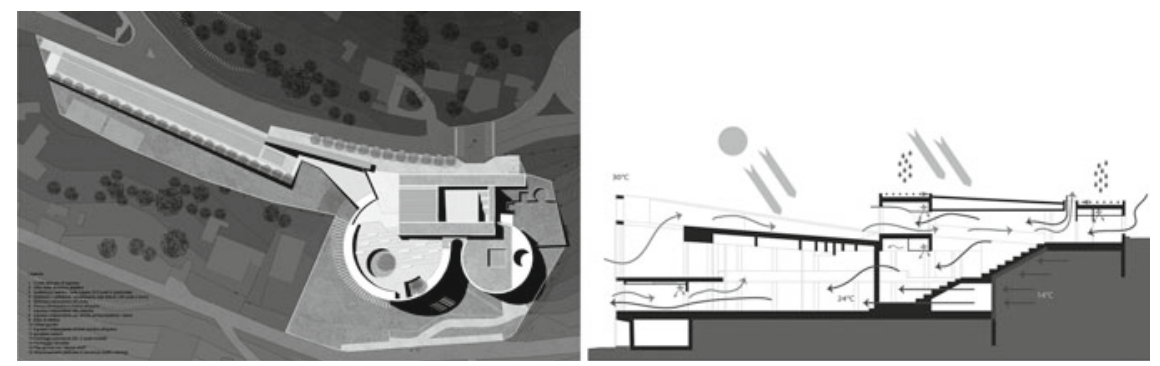

Fig. 6 Site plans of the school complex at $+266,85$ level (ground floor); Section, scheme of the bioclimatic operation (summer) and the passive cooling of the middle school building, chosen as strategies to reduce operational energy consumption

\section{Middle School at Sorbolo, Parma, 2016 ${ }^{3}$}

\section{@ Scuole Innovative National Competition}

The project for the new middle school at Sorbolo is part of the existing sports complex, acting as the pivot of a system of cardinal axes. However, it is also intended as part of a larger project on an urban scale that, with the addition of the Elementary School, will structure the entire school "campus": the future new educational center of a rural river consolidated landscape. The school's architecture is based on two main aspects: the geometry of distribution and spatial system; the timber construction technique and its aesthetics.

Considering the opportunities of opening in the whole day and for extracurricular activities, we wanted to propose a scheme that can be sectioned into two parts that can be used independently. An entrance area contains activities that are most oriented to the external use (atrium, conference room refectory, tower-library, extracurricular activities, teachers, laboratories). A second area contains only the classrooms for the concentrated activity. A third educational area is outdoors, with botanical flowerbeds and an earth embankment as theater (Fig. 7, 8, 9, 10).

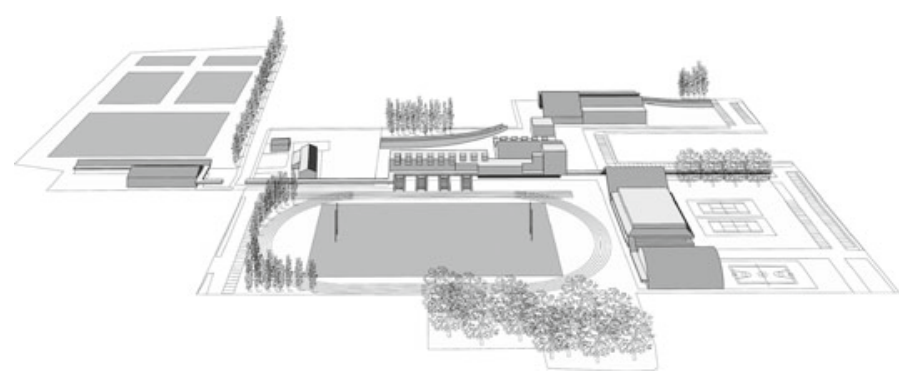

Fig. 7 General view from the east of the school complex

\footnotetext{
${ }^{3}$ Team work: Luca Monica, Elena Bonelli, Luca Bergamaschi.
} 


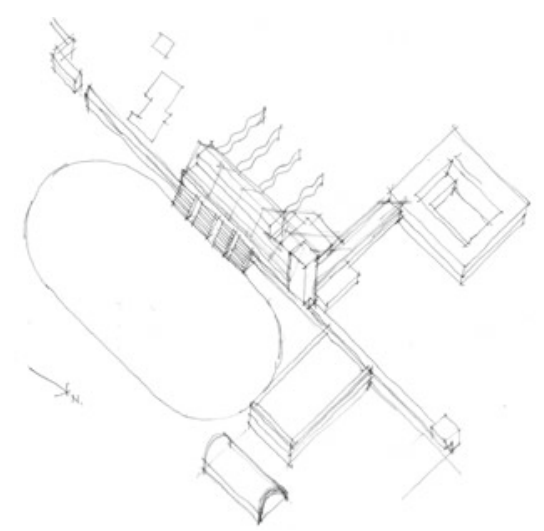

Fig. 8 Early drawing of the school complex

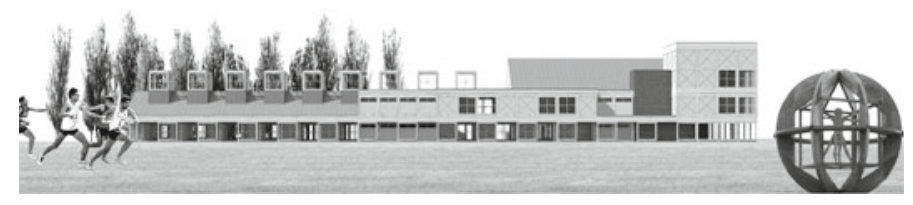

Fig. 9 View from the east, from the athletic field

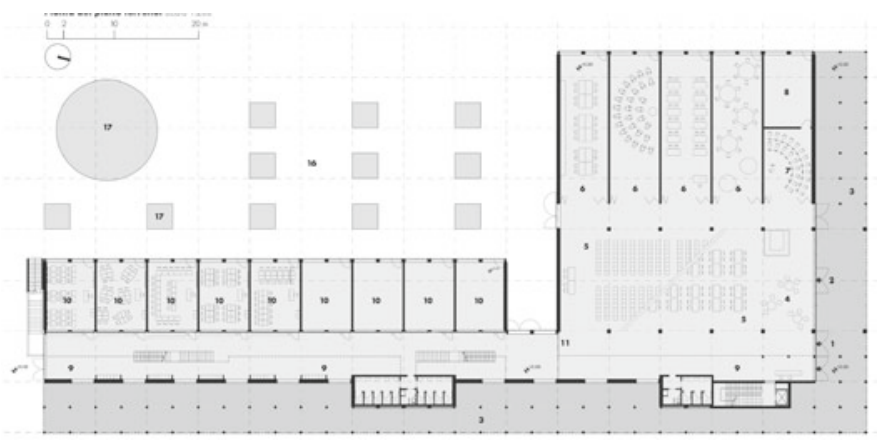

Fig. 10 Plan of the ground level

\section{New Lower Secondary School in the Municipality of Casatenovo (LC), 2016}

The area allocated to the new secondary school in the Municipality of Casatenovo is located south of Via San Giacomo, a highly important thoroughfare parallel to the

\footnotetext{
${ }^{4}$ Team work: Tomaso Monestiroli, Luca Cardani, Riccardo Nana.
} 
Roggia Nava canal, which feeds a large area of agricultural parks where historical and architectural villas are located.

It is a slightly elevated area which enjoys a beautiful landscape especially to the north, earmarked as a resource of great environmental value. These features make the area significant, and it can be further enhanced by the placement of a public building whose value goes beyond its own use, as the area also benefits from the environmental quality of the place where it stands.

We now know that the type of a building is defined by the relationship between its internal and external factors. External factors are related mainly to the characteristics of the place, the road network and the access system. Internal factors are related to the building's functionalities.

It is necessary to establish a harmonious relationship between these factors in order to create a suitable place for the activities that take place there, but at the same time to be able to embrace the character of the environment in which it stands, especially when, as in this case, it is a place of great beauty.

The choice at the core of the typological layout is to distribute all the parts of the school around a long gallery facing north-east with a continuous series of large openings facing the school's green area, partly intended for sporting activities and partly for a large garden that strengthens and gives shape to the many existing plants. The gallery is two stories high. Upstairs, a continuous balcony distributes the classrooms and looks out onto the landscape.

This gallery is the backbone of the entire typological layout; it is the distribution point of the building's two floors but also, and no less importantly, the meeting place of the entire school population. Along the gallery south-facing classrooms and laboratories lie, to the north are the gym and the auditorium which, located at a distance opposite to each other, are brought together through the school's large garden. The series of classrooms ends with the refectory to the east.

The functions distributed from the gallery are as shown in the competition notice. On the ground floor there are seven educational laboratories, a library and rooms for the administration offices and teaching staff; there are eighteen classrooms on the first floor, three for each of the six sections. Each classroom has a wall with a continuous series of large openings facing east or west. In the latter there is a sunshade and a mechanical shading system as shelter from the sun during the hottest hours.

The north-east side of the gallery contains: the ample-sized gym for different sports (volleyball, basketball, handball etc.) and other equipment for freestyle exercises. A flight of steps on the long side of the gym overlooks, in addition to the indoor and outdoor playgrounds, the garden, and at the bottom of the latter, the auditorium. The auditorium is one big square-plan classroom that distributes the audience across three sides with a wooden staircase, under which the necessary storage area is to be found.

The orderly succession of one singular element, a pillar with a circular section that is repeated every $2.60 \mathrm{~m}$ and runs along the entire perimeter of the building and the two collective buildings, the gym and the auditorium, has this dual role: to give a grand formal unity to the entire building and to allow for large distribution flexibility within (Figs. 11 and 12). 


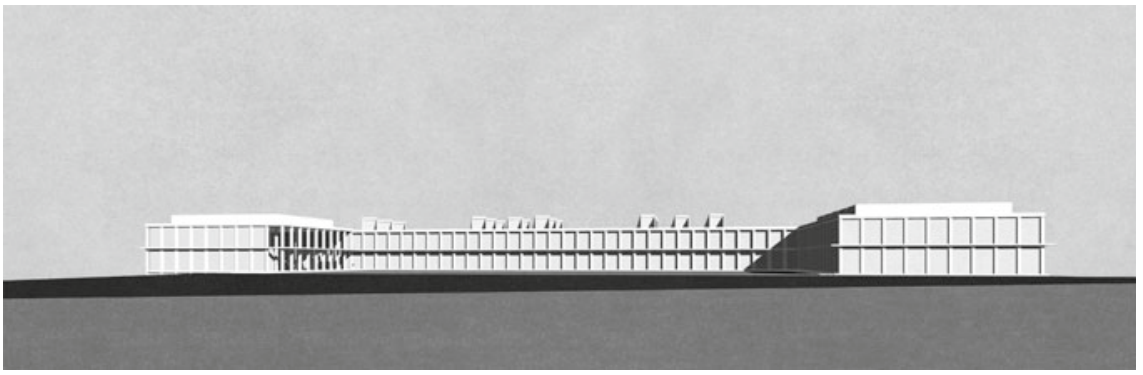

Fig. 11 View of the northern courtyard

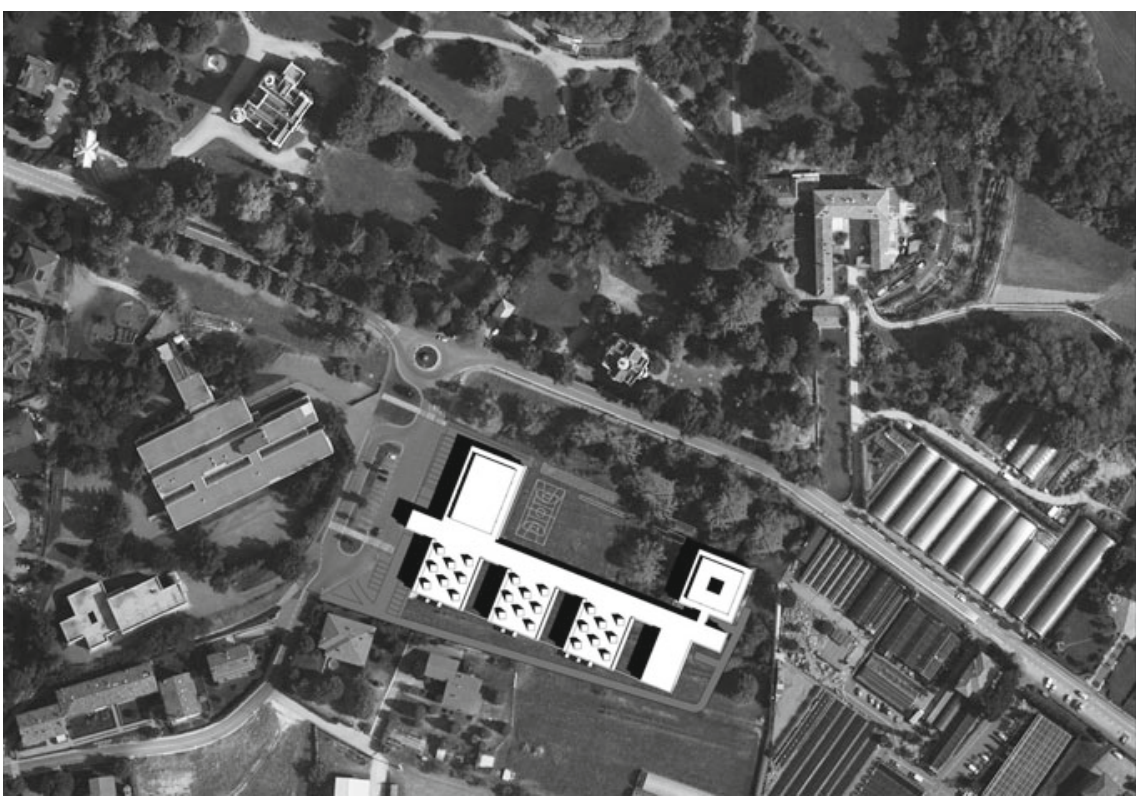

Fig. 12 General plan

\section{Design for Nearly Zero Energy Building (NZEB) Middle School at Casatenovo (LC), 2016}

The design project's layout responds to the purpose of "founding" a suburban-rural site, as well as to the complexity of school buildings acting as civic centres and to the challenge of integrating the issues related to 3.0 teaching innovations with the continuous reflection on learning architecture.

\footnotetext{
${ }^{5}$ Team work: Laura Anna Pezzetti (architectural design); Claudio Del Pero, Mario Maistrello (energy); G. Piantato (structures).
} 
Reflecting on the asymmetry of the nearby Quattrovalli Farmstead'layout, three blocks on two levels (classrooms, canteen, gymnasium) are staggered but interconnected along the longitudinal axis and the receded block of the multifunctional hall (auditorium, bridge-library, administration), to form an extended green forecourt and, in the rear court, the open-air sports field. The forecourt symbolically projects the raised solid of the library towards the town and the existing school complex in order to design a comprehensive landscape-i.e. "the education field". The hall is a public multifunctional square where a peculiar system of ramp ways starting in the hall and surrounding the auditorium, provides the library with an independent access from the learning spaces. The peripatetic device meets the design for all, stimulating spatial experience for all users.

Through an interdisciplinary approach, the design achieves a logical coherence between formal, technical and material choices, with particular reference to the selection of eco-compatible materials and technologies and to the reduction of net primary energy demand, GHG emissions, and energy costs. The synergic interaction between technological solutions has obtained a Nearly Zero Energy and Emission Building (NZEB): good thermal inertia; favorable orientation, brise-soleil, adjustable sun screens; radiant floor emission assisted by an air handling system to control relative humidity; air-to-water electric heat pump; photovoltaic system on the roof (peak power of $80 \mathrm{kWp}$.) caverning equal to approximately the $70 \%$ of the energy needed for HVAC purposes; thermal storage. The dynamic energy modelling of the building was carried out using the (BEST-Polimi energy simulation tool based on the EnergyPlus engine) expected annual consumption of electricity for heating, cooling and DHW production is estimated at about $130,000 \mathrm{kWh}$, corresponding to $27 \mathrm{kWh} / \mathrm{m} 2$ (Figs. 13, 14 and 15).
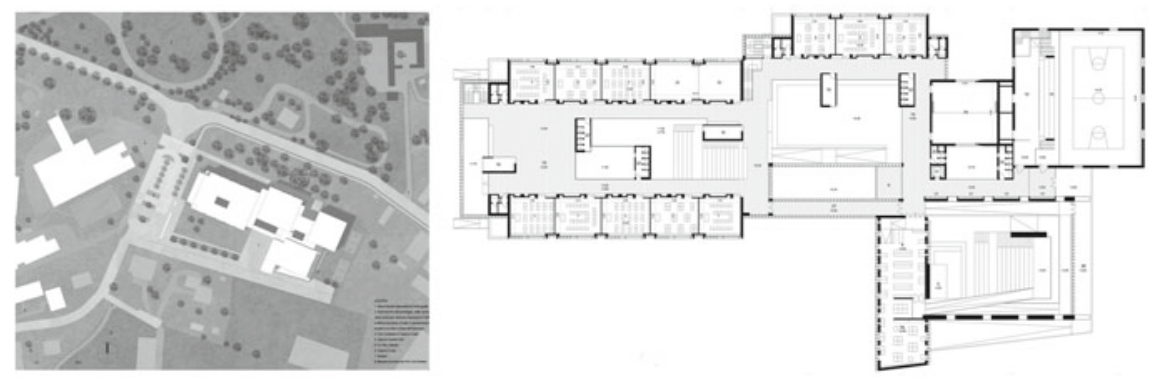

Fig. 13 Site plan and first floor plan 


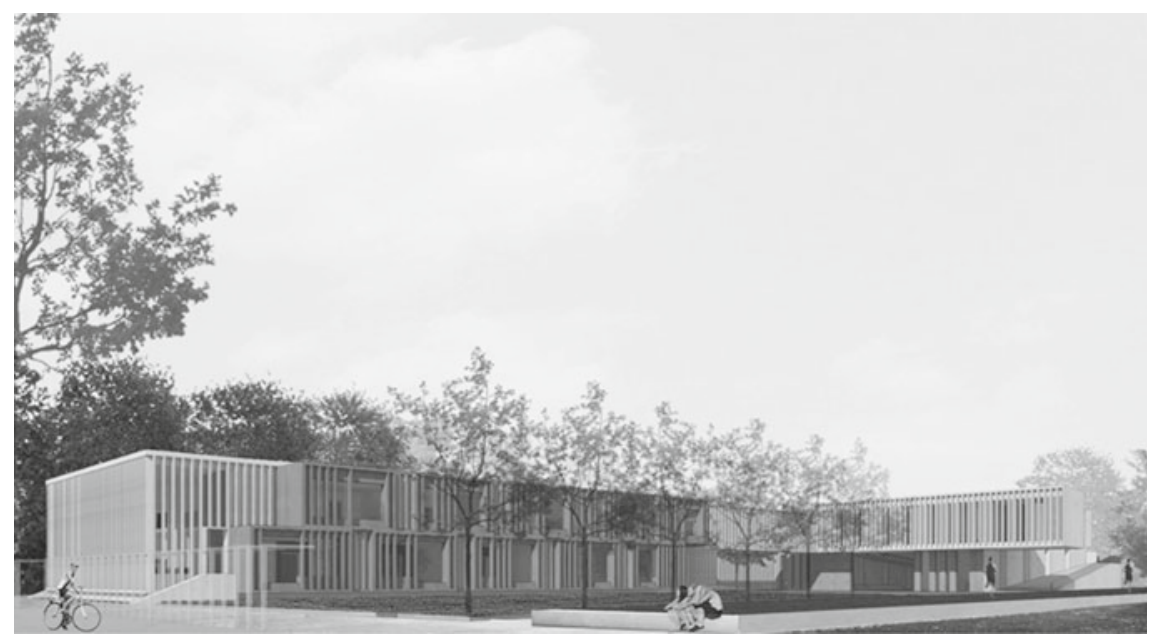

Fig. 14 View of the frontcourt, classrooms and library blocks from the entrance
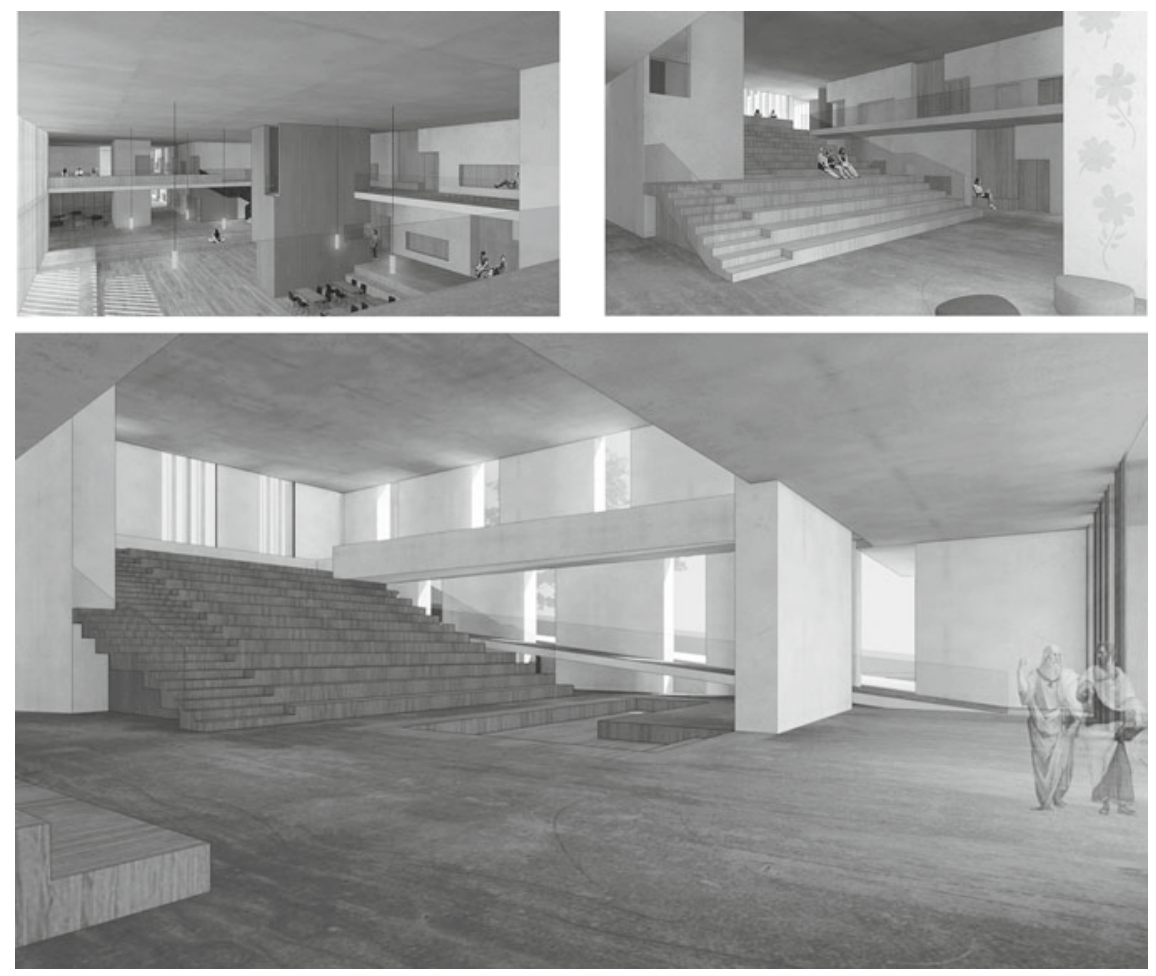

Fig. 15 Interior views of the canteen and "knowledge deck", classroom nave and multifunctional hall 


\section{Competition to Design the "Primary and Secondary School" in Bolzano, 2018}

The big garden is the heart of the school which looks onto all of its spaces: the classrooms, study and play areas, laboratories, the canteen and collective areas. The garden, open to the landscape, is surrounded by a full-height pergola which gives unity to the different parts that make up the school, and it also protects its interiors from the sun.

Study areas are located on two floors in the two buildings facing each other across the garden, connected by a glass gallery. The canteen, which occupies the ground floor on the north-east side, looks out directly onto the garden.

The classrooms are surrounded by spaces for students' free activities. They are configured like luminous islands attachable through large openings, according to different configurations.

Collective activities included in the school, gym, auditorium-theatre and the library, are located along the north-west side of the garden, at the end of the axis that leads to the river. Each one is identified by a different volume which makes them recognisable. Connected between them and to the classrooms (albeit with independent entrances), they are higher in order to affirm their urban relevance and to appropriately conclude the long open view towards the river.

The courtyard in the middle of the project, a genuine "rain garden," has a strong micro-climatic impact.

The natural relationship with the courtyard, with its considerable pedagogic value, is accentuated by the presence of large, full-height glass facades which favour the use of natural ventilation during the summer season, also through the thermo-mitigating effects of the garden. The height-adjustable pergolas shield the facades from solar radiation.

The natural ventilation is supported by the direct air reaction which is activated in the classroom's cross-connection pass-through areas, interacting with them (Figs. 16 and 17).

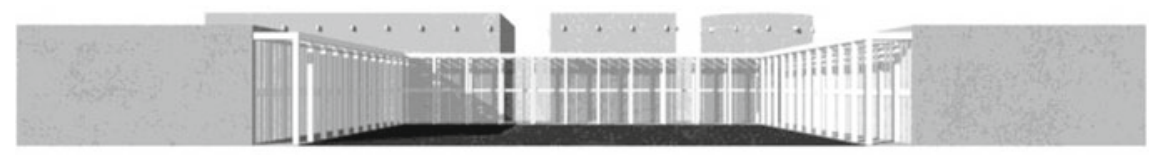

Fig. 16 Raingarden courtyard view

\footnotetext{
${ }^{6}$ Team work: Tomaso Monestiroli, Raffaella Neri, Paolo Oliaro, Sergio Croce, Luca Cardani, Giovanni Uboldi.
} 


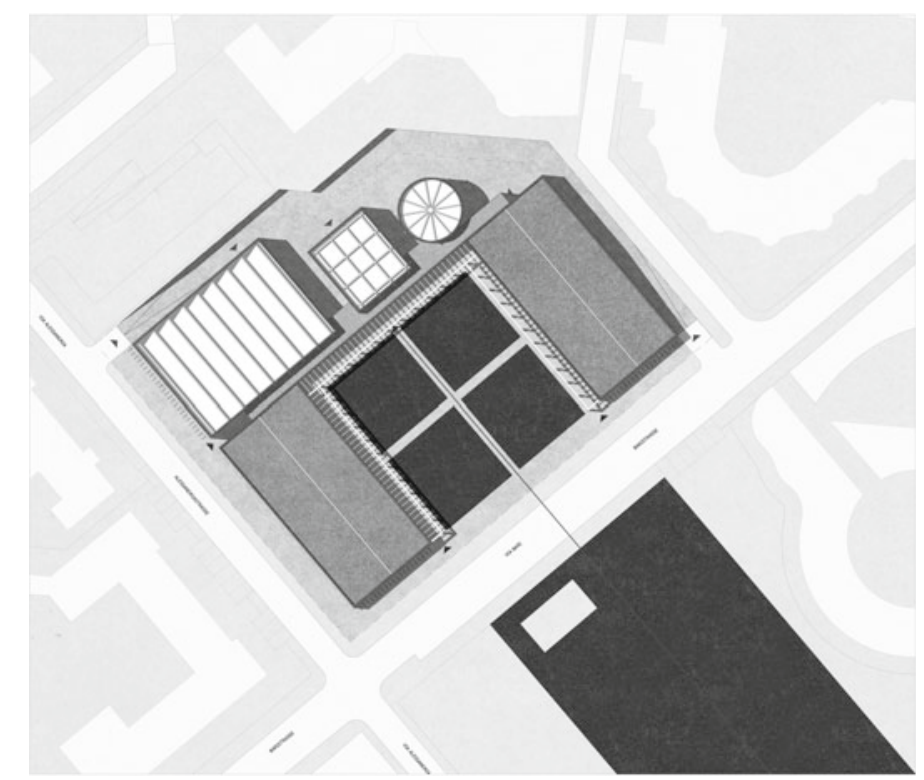

Fig. 17 General plan

\section{New Academy of Music in Krakow 2016 ${ }^{7}$}

The proximity of the Vistula River and the large green area in front of the project area make the place an extraordinary opportunity to build the new Academy of Music in a context dominated by nature. We believe that the issue of the relationship with nature is the main theme of our times and should influence the shape of the city and the architecture that determines it.

That is to say that the occasion of the competition is not only to design a school, but to define a growth hypothesis of the city which includes natural places. From the project area there is a view of the river, the woods that flank it and, farther away, the historic city of Krakow. An extraordinary site, in short, meant for public activities such as the school of music, a future large auditorium and various sporting activities in the green areas along the river.

The first choice made was to not place the new Academy of Music in only one building but to spread it across five separate buildings, aligned together and following the lope of the land facing west towards the future urban park and in the direction of Krakow old town. The relationship with the green areas is the foundation of the type of buildings that are arranged and oriented according to this general objective. The two buildings with classrooms are arranged at the centre of the linear system at the point where the project area changes direction. Even these buildings are adapted to

\footnotetext{
${ }^{7}$ Team work: Tomaso Monestiroli, Raffaella Neri, Luca Cardani, Maurizio Acito, M. Guazzotti, Giovanni Uboldi.
} 
the land's rotation, creating a central place from which there are two wings, defined by the two aligned buildings that house the school areas and the premises of the rectorate, facing towards the landscape. Two small tower buildings will house 15 apartments required for guests and students.

The music school building located further north is the first to be reached by road. It is a linear building that is spread over three floors with the classrooms specified in the notice on both sides. To the west towards the park, there are four large classrooms for rehearsals, the orchestra, the lyric theatre, the choir and the organ. They are especially high classrooms measuring $16 \mathrm{~m}$ to ensure maximum acoustic efficiency, with an internal gallery measuring a height of $8 \mathrm{~m}$, which allows for a steel external gallery to be reached, from which the landscape can be seen. Directly connected to the linear body of the school, where it is accessed from, these classrooms are enclosed in exposed brickwalls, respecting a building tradition that is highly palpable in the historic centre of Krakow.

The auditorium is the most important building of the entire facility and is located next to the library in the centre. In this way, a formal hierarchy is created between the two buildings open to the public and those intended for the school. The auditorium will also have a perimeter of pillars clad in exposed brickwork to emphasise its public purpose and its civic value. The interior of the building is a large rectangular-shape hall with a variable height appropriate to its acoustic performance where different areas are identifiable.

The library is constructed in a similar way to the auditorium with a perimeter of pillars clad with bricks. The building is arranged over four floors of reading rooms revolving around a central space lit by a large skylight which diffuses the light from above to all four levels. Each of the reading tables are placed near a large window opening out onto the landscape.

Near the library is a small residential building with 8 floors containing 15 apartments of about $40 \mathrm{~m}^{2}$ each, consisting of a living room with kitchenette, a twin bedroom and a bathroom. Similarly, in this case, the building is clad in exposed brickwork.

The rectorate building concludes the series of the school buildings. This has the same linear type and the same construction form as the music school (Figs. 18 and 19).

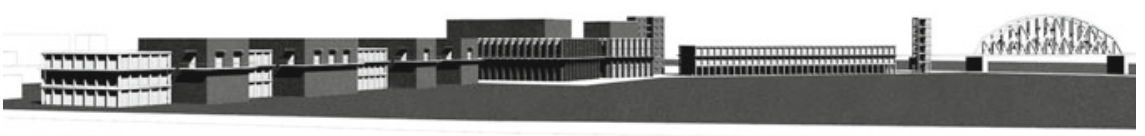

Fig. 18 General view 


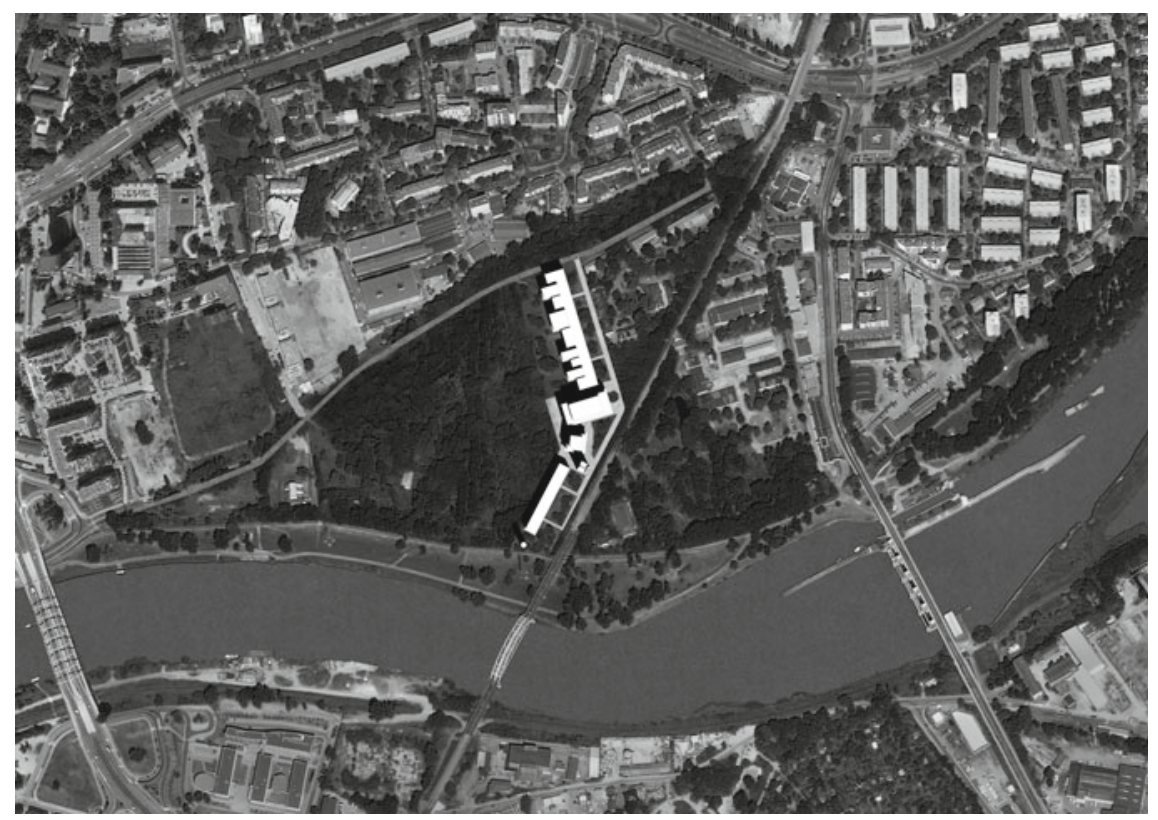

Fig. 19 General plan

\section{Competition for a Kindergarten in Dolzago (LC) ${ }^{8}$}

The urban island on which the project area is located-between the streets Montecuccoli, Parini-Piazza della Repubblica, Corsica and Donatori di Sangue-is made up of structures with different functions: the Bonomelli's factory; the large urban Alpini park; the Town Hall building and the new public car park area. Once the quantities relating to the different equipment are defined, the architectural layout is organized favouring some features regarding physical aspects, location and topography. The distribution of the required activities favours the placement of the spaces for the classrooms in the southern part, while the collective ones are in the northern part, towards the Alpini park.

The difference in height between the street level and that of the project is assumed as a resource, arranging, in correspondence with the secondary access on via Montecuccoli, the service spaces, the kitchen and, finally, in the existing underground floor, suitably transformed, the mechanical and heating systems. The layout of the spaces gives priority to the southern-west location of the classrooms, divided into three blocks around two intermediate garden patios, designed in continuity with the covered interior space. The layout of the classrooms is organized with different equipment: a space for free activity and one for planned activities. This space is not physically divided, but can be separated with the chance of being easily set up with

\footnotetext{
${ }^{8}$ Team work: Domenico Chizzoniti, Gloria Asnago, Emanuela Margione, Alessandra Rossi.
} 
mobile furnishings, depending on the programming of different educational activities. The arrangement of the three sections on the south-west side in a radial pattern has allowed the construction of a versatile autonomous system in direct contact with the open space for free activities in the school garden.

A more protected intermediate space, the patio, is open to the interior space, through large openings in correspondence with the spaces destined for free activities. Each of the three sections is set up with different equipment, while the spring one, located close to the atrium of the main entrance, is equipped with a resting room for the younger children. The design of the outdoor space is carried out in continuity with the internal one. A suitable space is reserved for each classroom as a free outdoor area that serves as a living room, in continuity with the internal environment and as a link between open and closed spaces. These recesses, called "patios" have the function of connecting the spaces of the classrooms and provide sufficient natural light for indoor activities. Particular attention is paid to the differentiation of façade materials in order to support the conception of architectural bodies with the use of large windows, shielding elements, wooden doors and windows. Therefore, different colour choices are adopted in the façade cladding, giving to the materials the connotation of the different functions (Figs. 20, 21 and 22).

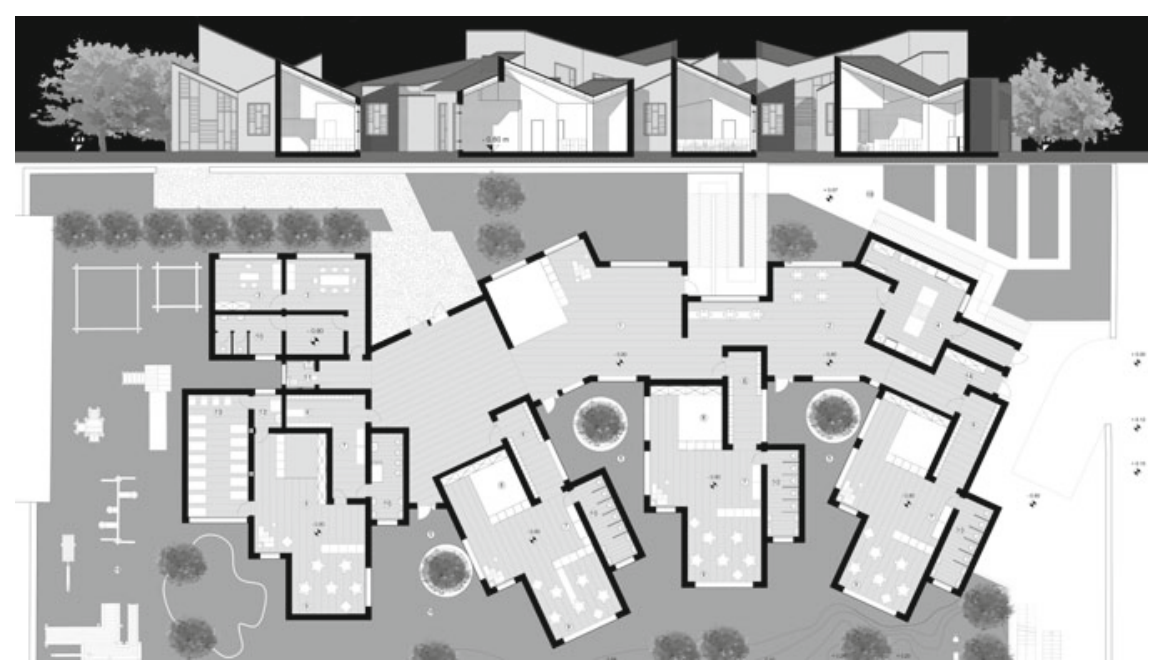

Fig. 20 General plan and longitudinal section 


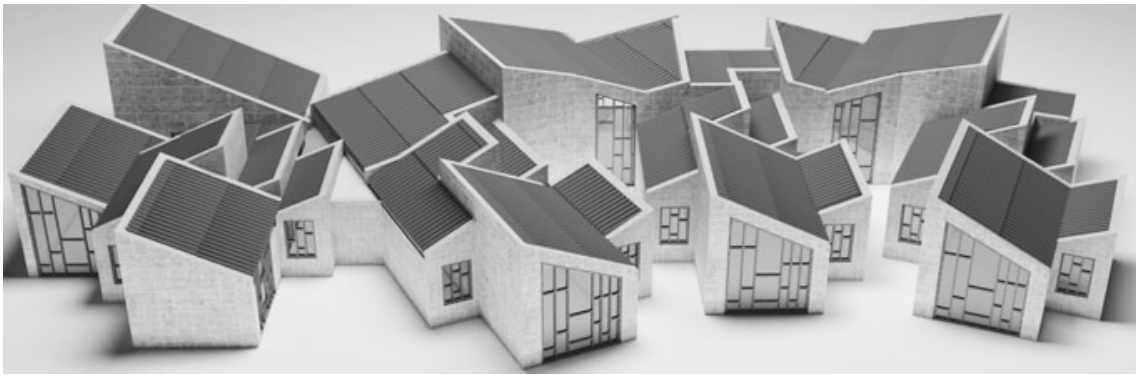

Fig. 21 Physical model

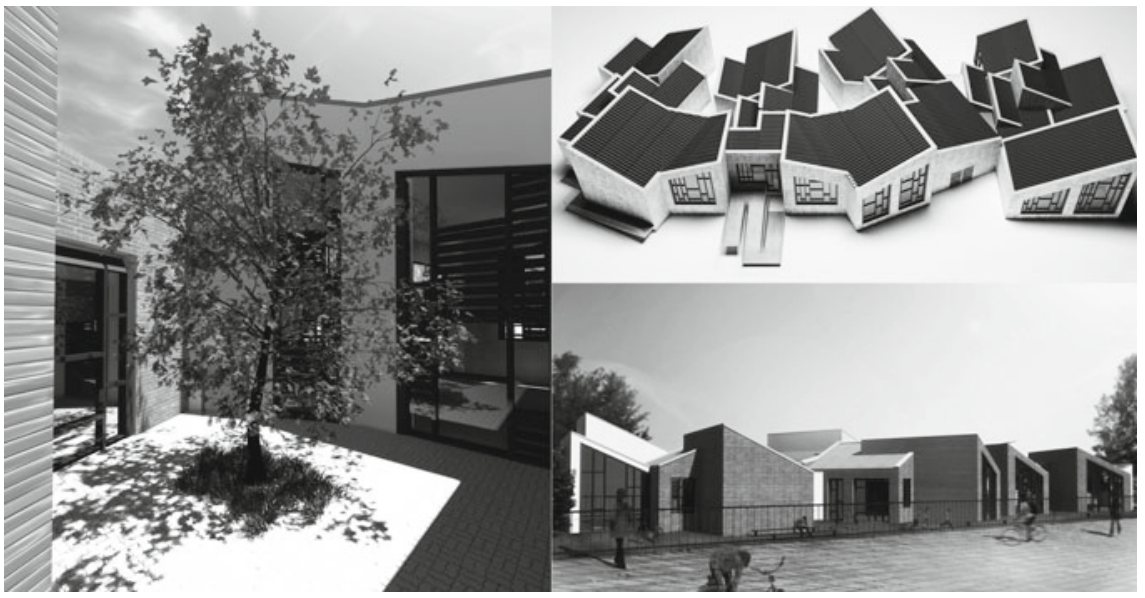

Fig. 22 Courtyard view; physical model view; elevation view

\section{Kindergarten in Lurago D'Erba (Co), 2018}

The topography of the place and the beauty of the hilly landscape evoke the nursery's features, its location and its relationship with the surroundings.

The nursery is set on the gentle slope of the hill sloping towards the west: two masonry walls enclose the green spaces of the schools connected to each other but separated by walls of various heights. As a result they will define a large lawn all around the existing primary school, making future outdoor sports possible, and a more protected green terrace, belonging to the new nursery. The terrace, facing the countryside sloping down into the valley, is at the heart of the nursery and onto which all of its interior spaces are overlooked. These are dug into the sloping ground, forming terraces that do not obstruct the view of the houses above.

\footnotetext{
${ }^{9}$ Team work: Raffaella Neri, Sergio Croce, Elsa Garavaglia, Claudia Angarano, Alessia Cerri, Marvin Cukaj.
} 
All spaces face old Durini factory and the lake's mountains, the true heart of the school complex and the settlement that surrounds it. The Leonardesque sweetness of the Brianza foothill landscape becomes the schools' quality element.

The nursery is set in terracing built at the level of the school, on the lower part of the slope, so as not to hinder the open views from the Via Madonnina and the houses above. Another level jump separates and protects the gardens of the two schools from the surrounding countryside: the valleys are bordered by a wall, which internally is, has the height of a parapet in order to leave the view open.

More than anything else, the nursery school is a metaphor for a house. It is the place where the child feels protected and develops the first forms of socialisation and learning through play.

As in a big house, it is accessed through the school garden, skirts the wall of the viewing point arrives at, you reach the terrace and through the porch, a modern portico for games and parking, which leads into the large common glass area. A wall that serves as a stage for theatrical performances and games reveals the canteen; the furniture can be changed around.

Sections are organised around five cloisters which allow the light to enter. Each one has an L-shape around its patio, a cosier place for outdoor games; through the glass walls, the common space can be spotted and, beyond this, the garden and the mountains. Outside to the south-east, the masonry wall borders a shady and cool space for games with different flooring. On the opposite side, on the wall facing south, there is a sunny area intended for educational gardens.

The nursery's green roof establishes continuity with the hill's slope.

The main entrance is from the car park to the north of the area; a secondary entrance is located to the south-west, linked to the cycle path. A final service entrance is located to the south-east and provides access to the technical rooms and kitchens across a service road that runs parallel to the cycle path (Fig. $23 \mathrm{a}, \mathrm{b}$ ). 
(a)

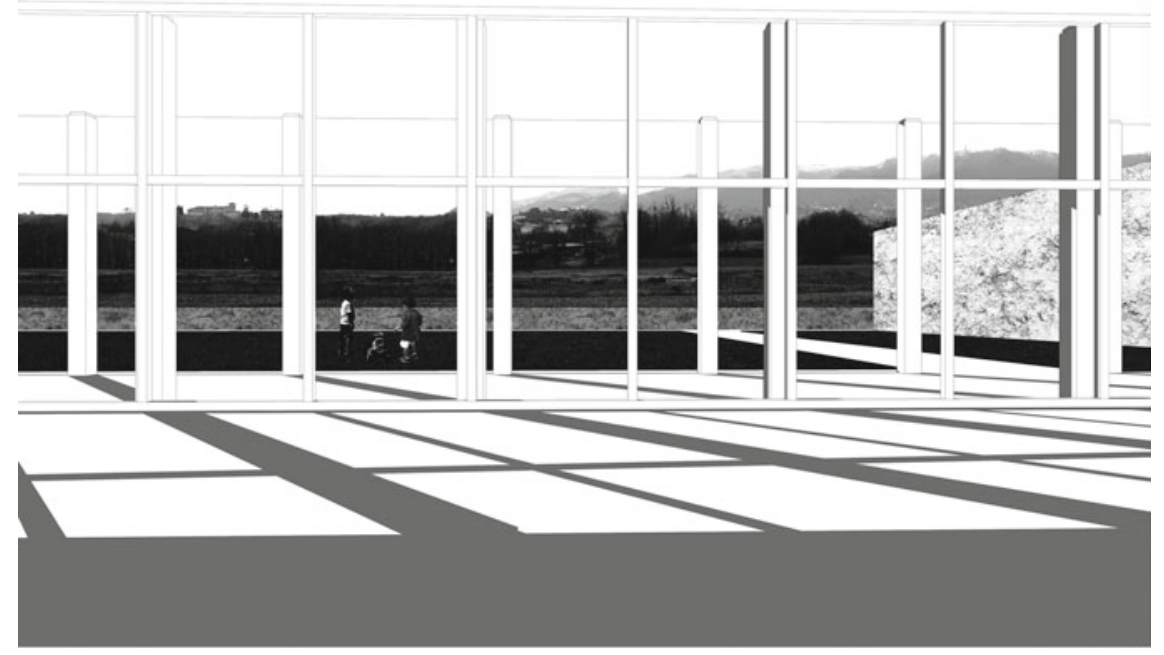

(b)

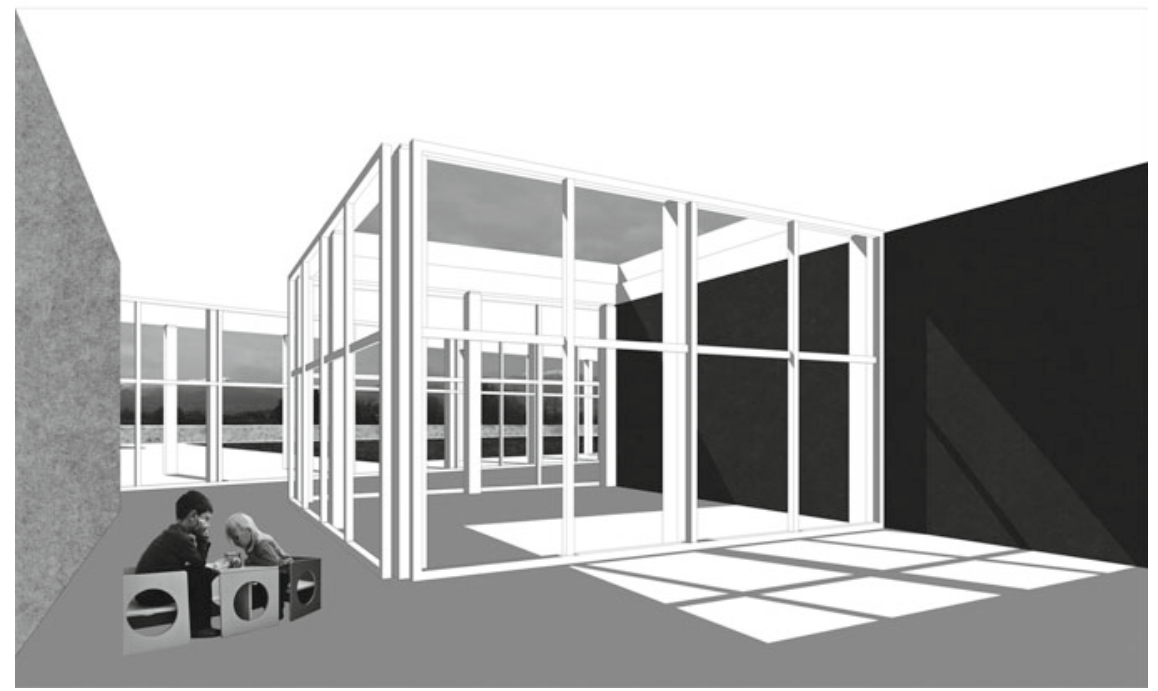

Fig. 23 Perspective views from the inside 
Open Access: This chapter is licensed under the terms of the Creative Commons Attribution 4.0 International License (http://creativecommons.org/licenses/by/4.0/), which permits use, sharing, adaptation, distribution and reproduction in any medium or format, as long as you give appropriate credit to the original author(s) and the source, provide a link to the Creative Commons license and indicate if changes were made.

The images or other third party material in this chapter are included in the chapter's Creative Commons license, unless indicated otherwise in a credit line to the material. If material is not included in the chapter's Creative Commons license and your intended use is not permitted by statutory regulation or exceeds the permitted use, you will need to obtain permission directly from the copyright holder.

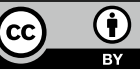

